\title{
DZIKIR DAN FIKIR SEBAGAI KONSEP PENDIDIKAN KARAKTER: TELAAH PEMIKIRAN KH. MUNAWWAR KHOLIL AL-JAWI
}

\begin{abstract}
Muhammad Anas Ma`arif Institut Pesantren

KH Abdul Chalim Mojokerto anasdt16@gmail.com

Muhamad Husnur Rofiq Institut Pesantren

KH Abdul Chalim Mojokerto umasoviq@gmail.com

This research is motivated the dimension of dhikr which is oriented to form a clean heart, the dimension of thinking forms a human with high intellectual (perfect reason). The implications of the integration of dhikr and thought will form an integral concept of education without dichotomy. From the moral knowing, moral feeling and moral action components which are combined with tazkiyatun nafs, it is expected that students can practice the values embodied in the goals of character education.

Purpose of this study aims to describe and analyze the dhikr and fikir according to KH Munawwar Kholil Gresik in the book of Faidhul Illah and its implications with the character dedication. Design/methodology/approach-of this research uses library research from the data of books that have been collected relevant to the theme.The results shows that he integration of dhikr and fikir as the concept of non-dichotomic character education. Dzikir continuously and systematically thinking will bring out the character of the learner is integral. Originality/value-Dhikr (tazkiyatun nafs) and fikir (knowledge) form the whole human character (ulul albab) as the concept of integralistic character education. Character is not only in form through cognitive learning but also necessary habituation of religious activities.

When the dimension of dhikr which is oriented to form a clean heart, the dimension of thinking forms a human with high intellectual (perfect reason). The implications of the integration of dhikr and thought will form an integral concept of education without dichotomy. From the moral knowing, moral feeling and moral action components which are combined with tazkiyatun nafs, it is expected that students can practice the values embodied in the goals of character education.
\end{abstract}

Keywords: Dzikir, Think, Character Building 


\section{PENDAHULUAN}

Dalam Azymardi Azra (2012:7), manusia merupakan mahluk yang sangat mulia, unik dan kompleks yang terdiri dari bagian-bagian yang semuanya tidak bisa dipisahkan satu sama lain. Sedangkan dalam Imam Suprayogo (2014:14), manusia terdiri dari jasad, pikiran (akal), nafsu, hati dan ruh. Manusia tidak seperti binatang sebagaimana hanya terdiri dari bagian jasad dan nafsu. Mahluk yang disebut khalifah fil ardhi sering tidak bisa memahami potensi yang dimiliki dalam dirinya sendiri. Dari salah satu kompoenen tersebut maka cara dan merawatnya juga berbeda. Jasad dan hati mempunyai struktur dan bagian yang berbeda sehingga dalam merawat salah satu komponen manusia diperlukan caracara yang berbeda.

Hati merupakan salah satu piranti manusia yang jika dalam bahasa arab disebut qolb. Qolb secara bahasa yaitu segumpal daging yang terletak disebelah dada kiri. Sedangkan arti kedua adalah pengertian yang halus yang bersifat ketuhanan dan rohaniyah yaitu bersifat manusia yang dapat menangkap pengetian, pengetahuan dan arif (Al-Ghazali, 2007:124). Hati merupakan kekuatan penentu dalam pembentukan karakter perilaku manusia apabila hati sakit maka perilaku akan jelek dan begitu juga sebaliknya jika hati sehat maka perilaku manusia akan sehat.

Agar perilaku senantiasa baik maka perlu pembiasaan melakukan olahraga hati yaitu dengan dzikir. Dzikir adalah amalan yang dilakukan secara terus menerus agar tercipa kondisi hati yang bersih sehingga membekaslah suatu perilaku manusia yang baik. Cara dalam berdzikir sangar vaiatif, dari dzikir dengan suara keras hingga dzikir tag bersuara.

Karena struktur manusia tidak terdiri dari hati saja maka perlu juga mengembangkan potensi akal agar seorang menjadi dan mempunyai derajat yang tinggi. Akal adalah alat untuk berpikir sehingga manusia bisa mencapai derajat yang tinggi hanya dengan mengembangkan potensi akal yaitu dengan berpikir tentang ciptaan Allah. Diriwayatkan oleh Abi Dzar bahwa "berpikir sesaat lebih utama dari solat semalam suntuk" (Munawwar, 2011:25). Dalam hal ini berpikir adalah melakukan aktifitas pengetahuan seperti belajar, mengajar atau segala 
aktifitas tentang ilmu pengetahuan. Sehingga aktifitas manusia tersebut mengakibatkan penemuan yang terarah kepada suatu tujuan yang dikehendaki (Ngalim, 2014:43).

Kedua elemen dasar psikis manusia tersebut baik qolb (hati) atau aql (akal) saling berperan dalam mengikat psikis nafsu manusia. Nafsu agar tidak menguasai diri manusia maka manusia harus sering melakukan dzikir yang mana tujuan dzikir adalah membersihkan hati dari nafsu yang jelek seperti kikir, sombong, dengki dan lain sebagainya. Pengikat nafsu yang lain adalah akal yang mana apabila manusia bisa mengguankan akalnya dengan baik maka manusia tersebut adalah bisa mengikat hawa nafsunya. (Baharuddin, 2007: 115).

Dari pemaparan tersebut bagaimana manusia bisa menjadi pribadi yang utuh sesuai dengan tujuan islam yaitu bahagia dunia dan akhirat. Maka tidak sepatutnya selalu berdzikir hingga tidak melakukan aktifitas berpikir sama sekali atau sebaliknya selalu berpikir tentang pengetahuan tetapi lupa dengan esensi hidup manusia yaitu akhirat. Dari sinilah permasalah yang akan peneliti ungkap bahwa integrasi dzikir dan fikr diperlukan terlebih lagi bagaimana implikasi dzikir dan fikir berperan dalam pendidikan karakter.

Peneliti tertarik dengan pemikiran KH Munawwar Khalil karena beliau memilki karya yang sangat banyak dalam hal tasawuf terutama dzikir. Ada yang unik dari pemikirannya yaitu meskipun beliau seorang yang sufi akan tetapi beliau tidak meninggalkan kebiasaan berfikir yaitu selalu menulis (mengarang) kitab hingga akhir hayatnya.

\section{METODE PENELITIAN}

Penelitian ini menggunakan pendekatan kualitatif dengan jenis penelitian kepustakaan (library research) yaitu dengan mengumpulkan data-data dan bahanbahan yang berkaitan dengan tema pembahasannya. Dalam hal ini terdiri dari dua sumber. Sumber primer yaitu kitab faidul illa yang ditulis oleh KH Munawwar khalil (Munawwar, 2011, 59). Dan sumber skunder yaitu data-data pendukung untuk menganalisis pemikiran KH Munawwar. Seperti buku-buku yang berhubungan dengan tema yang dikaji yaitu: Badrul Alam ala Nahjil Atam, karya 
KH Munawwar Kholil, Tafsir Qurtubi, karya, Abi Abdillah Muhammad bi Ahmad Abu Bakar Al-Qurtuby,Tanwir Al Qulub fi Muamalat Allam Al-Guyub karya Muhammad Amin Al-Kurdy, Tafsir Inbu Katsir karya Abil fida` Ismail bin Katsir, Tasawuf sebagai kritik sosial, karya KH Said agil Siradj, dan beberapa buku lain yang sama dengan pembahasan penelitian ini.

Mengingat penelitian ini difokuskan kepada teks/data yang diperoleh dari kitab Faidul illah sebagai data primernya, maka peneliti menggunakan pendekatanconten analisys (Suharsimi, 2010:8), suatu penelitian dengan mengalisis isi buku. Untuk membantu keakuratan analisis peneliti menggunakan perbandingan pemikiran para pakar yang sependapat dengan $\mathrm{KH}$ Munawwar Kholil. Jika bertentangan maka penulis akan mengkompromikan.

\section{HASIL PENELITIAN}

\section{A. Biografi KH. Munawwar Kholil Gresik}

KH Munawwar lahir di Gresik 23 November 1952 H/ 22 Ramadhan 1805 H hari jumat pon setelah shalat ashar. Nasab beliau dari ibu tersambung hingga Sunan Giri (Raden Ainul Yaqien). Masa kecil tumbuh di desa Suci Kecamatan Manyar Kabupaten Gresik dan beliau belajar ilmu nahwu, ilmu fikih, ilmu sharaf dan ilmu bahasa pada ayahnya sendiri Kyai Adnan dan belajar pada Kyai Muhammad Amin, Kyai Ahmad serta Kyai Abdullah Faqih (ayahanda KH Masbukhin Faqih, pendiri pondok pesantren Mambaus Sholihin Gresik). Belajar qiroah pada Kyai Abi Dar, Kyai Ahmad Murshid dan kakeknya sendiri yaitu KH Muhammad Kholil. Tidak hanya belajar masa kecil beliau juga digunakan untuk bekerja menggembala kambing membantu orangtuanya dan beliau juga ditinggal wafat ayahnya ketika masih kecil. Kyai Adnan Ayahandanya orang yang miskin dan shalih ditunjukan dengan bahwa Kyai Adnan tidak pernah memakan makanan kalau tidak dari hasil kerjanya sendiri. Kyai Adnan suka berziarah kepada Ulama`ulama' dan meminta doa agar kelak anaknya dijadikan seorang yang sholih, orang yang selamat di dunia dan di akhirat.

Ibunda KH Munawwar yaitu Nyai Afwah semasa mengandung beliau selama dua belas bulan. Nyai Afwah adalah sorang yang sholihah. Beliau selalu 
membaca Al-Qur’an di waktu malam qiyamul lail hingga wafatnya. Nyai Afwah juga menjadi pengikut thariqoh Qodiriyah Naqsabandiyah. Beliau selalu berdoa kepada Allah Swt agar putra-putri beliau kelak menjadi orang yang shalih dan shalihah dan mendapat ridha Allah di dunia dan di akhirat.

KH Munawwar belajar di pesantren Darul Ubudiyah Roudlatul Muta allimin Jatipurwo Surabaya yang diasuh oleh KH Usman Al-Ishaqi (wafat 1984) pendiri thariqoh Qodiriyah Naqsabandiyah Al-Ustmaniyah. Selama di pesantren KH Munawwar belajar dengan sungguh-sungguh bahkan dikategorikan sebagai seorang yang cerdas. Disamping belajar beliau juga mengabdi Pada $\mathrm{KH}$ Ustman Al-Ishaqi. Selalu istiqomah menyapu halaman sebelum sholat subuh. Riyadhoh dan mujahadah dengan tidak memakan makanan yang dari beras selama 14 tahun. KH Munawwar berbaiat kepada gurunya murshid thoriqoh Qodiriyah Naqsabandiyah Ustmaniyah yaitu KH Ustman Al-Ishaqi dan memperbaharuinya pada mursyid pengganti gurunya putra $\mathrm{KH}$ Ustman yaitu KH. Ahmad Asrori Al-Ishaqi. Beliau di pesantren selama 24 tahun hingga akhirnya membangun pesantren di tempat kelahiran dengan nama Daruttaqwa yang diresmikan oleh H Amiseno Bupati Gresik Tahun 1987.

Karya-karyanya adalah: (1) Tasfiyatul Qulub, (2) Badrul Alam ala Nahjil Atam, (3) Auliyaul Falihin I, (4) Auliyaul Falihin II, (5) Faidul Illah fi Fadli Dzikrullah,(6) Ajwabul Mardhiyyah, (7) Naful amim bisarah Minhajul Qowim 4 jilid yang belum selesai tetapi sudah di tinggal wafat olehnya. KH Munawwar wafat pada hari selasa 28 November 2012.

\section{B. Pegertian Dzikir}

Dzikir secara bahasa yang diambil dari bahasa arab dzakara yang berarti mengingat, memperhatikan, mengenang, mengambil pelajaran, mengenal atau mengerti, ingatan. Atau menyebutkan sesuatu dengan lisan atau di dalam hati (Mandzur, 2010:345). Sedangkan secara istilah dzikir adalah ingatan atau suatu latihan spiritual yang bertujuan untuk menyatakan kehadiran Tuhan seraya membanyangkan wujud-Nya. Atau suatu metode yang digunakan untuk mencapai konsentrasi spiritual (Riyadi, 2014:37). 
Menurut Mu`inudinillah (2014:20) dzikir adalah kondisi jiwa yang memungkinkan seorang untuk menjaga apa yang dimiliki dari pengetahuan, dzikir seperti hifdz, hanya saja hifdz atau hafalan merupakan penguasaan dan pengungkapan apa yang dihafal, sedangkan dzikir untuk menghadirkan atau mengingat. Dzikir juga dimaksudkan hadirnya sesuatu di hati atau di lisan.

Menurut Micon Dalam M A Subandi (2009:33), dzikir secara literal berarti mengingat, pada dasarnya merupakan amaliyah yang selalu terkait dengan berbagai ibadah ritual dalam Islam. Dalam pengertian ini dzikir berarti “ suatu bentuk kesadaran yang dimiliki oleh seorang mahluk akan hubungan yang menyatukan seluruh kehidupanya dengan Sang Pencipta".

Dzikir mempunyai dua makna: (1) Makna secara umum yaitu termasuk semua kajian objek ilmu syariat Ibnu Taimiyah menyatakan "dzikir yang lebih utama adalah membaca al-Qur`an”. (2) sedangkan dzikir secara khusus adalah segala sesuatu bentuk ketatan kepada Allah sebagai contoh, solat adalah dzikir, puasa adalah dzikir ibadah haji adalah dzikir (Alba, 2012:98).

Dari yang di paparkan di atas KH Munawwar lebih condong ke pengertian dzikir secara kusus yang di paparkan oleh Cecep Alba bahwa dzikir adalah segala bentuk ketaatan kepada Allah. Walapun definisi ini kusus tapi pengertianya lebih ke secara menyeluruh aktifitas bahwa segala bentuk ketaatan kepada Allah adalah dzikir seperti puasa, salat, haji. Bahkan Allah berfirman secara jelas.

Artinya: "Ingatlah kepadaku maka aku akan mengingatmu"

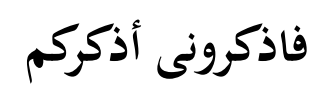

Dalam pengertian ini KH Munawwar (2011:13) menjelaskan bahwa dzikir adalah dengan bentuk taat dan patuh pada segala aturan Allah. Bahkan makna adzkurkum tidak hanya sebatas mengingat tetapi Allah akan memberi pertolongan, memberi pengampunan, memberi hidayah, memberikan derajat yang tinggi. Ibnu Abbas menjelaskan bahwa "dzikir adalah taat kepada Allah, barangsiapa yang taat kepada Allah maka ia telah berdzikir dan barangsiapa yang tidak taat maka tidak termasuk orang yang berdzikir".

Menurut Ibnu Katsir (2010:464), bahwa dzikir adalah mengingat dengan berbuat baik dan selalu bersyukur atas apa yang diberikan Allah kepada 
makhluknya. Dengan bersukur dan taqwa kepada Allah maka akan diberikan Rahmat dan tambahnya nikmat Allah. (Damasqy, 2010: 464) Dalam Tafsir Qurtuby (2010:460), bahwa dzikir adalah ingat kepada Allah dengan jalan melakukan segala apa yang diperintahkan dan menjauhi segala apa yang di larang. Segala sesuatu bentuk ketaatan kepada Allah adalah termasuk dzikir.(Qurtuby, 2010: 460)

Dzikir juga berarti menghadirkan Allah yang Maha hadir dengan kelanggengan ingatan dimanapun dan kapanpun (Munawwar, 2007:60 ; Nurcholish, 2006). Konsep 'Now Here'. Arti konsep ini adalah bahwa Tuhan sekarang ada disini. Charles Gai Eaton dalam Fahrur Razi (2016:22), bahwa ketika seorang sedang berdzikir, maka ia harus melihat atau dilihat oleh Allah, disamping dia harus sampai menemukan Allah sudah berada dihadapanya. Dzikir juga berarti membangkitkan daya ingatan, ingat akan hukum-hukum Allah, meneliti proses kejadian alam, dan juga berarti mengambil pelajaran dan peringatan. Pada dasarnya berdzikir atau mengingat Allah memiliki lingkup yang sangat luas bahkan bisa dikatan segala aktifitas atau perbuatan yang dilakukan dengan tujuan mengaharap ridha Allah (Syamsul: 2014:15).

Hal ini menunjukan bahwa dzikir tidak hanya berupa taat kepada Allah masalah ibadah akan tetapi segala hal yang menjadikan semakin ingat dan taat kepada Allah adalah dzikir. Seperti taat kepada Allah dengan selalu bersyukur atas nikmat yang diberikan, belajar untuk menghidupkan agama Allah (bidang pendidikan), mencari nafkah untuk keluarga (ekonomi kemandirian), memegang amanah ketika menjadi pemimpin (politik), dan dakwah dengan tradisi-tradisi keartifan lokal. Segala bidang masuk dalam kategori berdzikir apabila yang dilakukan dengan tujuan melakukan taat kepada Allah.

Dzikir dalam Al-Qur`an disebutkan sebanyak 191 kali. Yang tersebar dalam 58 surat dari 114 surat yang adala Al-Qur`an. Kata dzikir disebutkan paling banyak pada surat Al-Baqarah sebanyak 14 kali, surat shad 12 kali, al-Anbiya` 11 kali, surat thaha 9 kali, surat furqan sebanyak 8 kali di 53 surat yang lain disebutkan sebanyak kurang dari 8 kali (Baqi, 2010: 76-85). 
Sedangkan KH Munawwar (2011:5-67) hanya menyebutkan 20 ayat yaitu pada surat Al-Baqarah ayat 103, Al-An`am 52, Al-Kahfi 28, An-Nur 37, Al-A`raf 235, Al-Anfal 2, Al-Kahfi 46, Ar-Ra`du 27, al-Ankabut 45, Al-Isra`46, Al-Ahzab 35, Az-Zumar 63, Al-Hadid 16, Al-Jumah 10, Al-Munafiqun 9, Al-A`la 9, AlGhasiyah 21, An-Nasr, 3.

Ada dua macam dzikir yang umum dilakukan di kalangan sufi, yaitu dzikirjahr dan dzikir khofi. Dzikir jahr juga disebut dzikir lisan. Dimana orangorang membaca kalimat dzikir secara lahiriah dengan suara yang jelas (kadang cukup keras). Sebaliknya dzikir khofi atau disebut dzikir sirri atau qolbi dilakukan dengan menyebut nama Allah berulang-ulang secara batiniyah didalam hati, jiwa dan ruh. Sebagian kelompok sufi berdzikir dengan gerakan tubuh ritmis seperti yang dilakukan tarekat Qodiriyah Naqsabandiyah. (Subandi, 2009:35) Dzikir amalan keseharian tarekat Qodiriyah Naqsabandiyah terbagi menjadi dua. Pertama adalah dzikir nafi isbat (dzikir jahr) dzikir bersuara keras dengan melafadzkan "La ilaha illa Allah" sebanyak 165 kali. Kedua, dzikir ismu dzat yaitu dzikir sirri, dzikir didalam hati dengan menyebut "Allah, Allah, Allah" secara terus menerus (Ismail, 2008: 03-7).

Terdapat tujuh latifah yang menjadi sasaran berdzikir yaitu lathifah (1) latifah al-Qolb; nafsu yang ada padanya adalah : mencaci, keinginan, berbuat onar, ujub, gibah, riya dusta, lupa pada Allah. (2) latifah ar-Ruh bersarang padanya yaitu nafsu mulhimmah (3) latifah as sirr adanya adalah nasfu muthmainnah, (4) latifah al-khafi, berada padanya yaitu nafsu al-mardhiyyah (5) latifah al akfha /nafsu al kamilah (6) latifah an nafsi berda padanya nafsu al amarah (7) latifah al qolab berada padanya adalah nafsu radliyah (Aqib Kharisuddin, 2000: 40-44)

Dengan demikian dzikir menjadi proses tazkiyatun nafsi untuk mencapai ridha Allah dengan memiliki tingkatan-tingkatan yang memilki sarasaran pada hati manusia yang berbeda-beda kemudian terbentuklah suatu manusia yang utuh melalui dzikir karena sejatinya manusia terdiri dari struktur psikologi yang komplek. Sehingga dalam menjadikan tujuan ma`rifat bi Allah dengan menyucikan diri adalah membersihkan hati dengan berdzikir. Hati (qolb) 
merupakan pusat segala kelakuan baik manusia, apabila hati manusia baik maka perlakuan manusia tersebut seluruhnya baik jika hati manusia itu jelek dan kotor maka perilaku manusia tersebut juga kurang baik.

Meskipun hati manjadi pusat penggerak amal baik akan tetapi tidak dinafikan bahwa potensi akal manusia juga harus dikembangkan. Dalam hal ini adalah berfikir tentang ilmu pengetahuan (memikirkan ciptaan Allah), karena pada dasarnya manusia mempunyai derajat tinggi adalah karena diberi akal oleh Allah.Sedangkan orang yang menggunakan akalnya adalah orang yang mampu menguasai hawa nafsunya sehingga hawa nafsunya tidak bisa menguasai dirinya. Orang yang bisa mengendalikan hawa nafsunya adalah orang dapat memahami agama.

Berfikir tentang ciptaan Allah merupakan mengembangkan dan mengendalikan potensi akal manusia. Akal bukanlah otak sebagai salah satu organ manusia, tetapi daya pikir yang terdapat dalam jiwa manusia. Akal ini dapat memperoleh ilmu pengetahuan dengan memperhatikan alam sekitar. Oleh karena itu akal merupakan potensi gaib yang tidak dimiliki oleh makhluk lain, walaupun makhluk tersebut memiliki otak (Baharuddin, 2007:116). Akal adalah alat untuk berfikir, jadi, salah satu hakikat manusia ialah ia ingin, ia mampu dan ia berpikir (Ahmad Tafsir, 2012:17).

Sanusi mengatakan bahwa akal dan otak adalah sama. Otak merupakan organ terpenting bagi manusia berbagai tehnik dan metode untuk meningkakan kemampuan otak tersebut secara implisit menunjukan pentingnya peran otak dalam kehidupan. Otak dipandang sebagai pusat berpikir manusia. Berpikir itu merupakan aktifitas manusia yang penting dan bisa membuat manusia bisa mengembangkan kemampuanya dan bisa meningkatkan taraf hidupnya (Achmad, 2016:55).

Abu Darda` berkata bahwa "berfikir sesaat lebih baik dari pada melakukan shalat semalam suntuk". Sufyan bin Uyainah berkata bahwa "berpikir adalah cahaya yang masuk dalam hati". Disebutkan juga dalam sebuah riwayah bahwa "sebaik-baiknya ibadah adalah berpikir dan wara". Dalam hal berpikir tidak hanya peran otak semata akan tetapi ilham Allah juga turut dalam proses kekuatan 
manusia berpikir. Seperti halnya bagaimana kita taffakur tentang buaya yang tidak mempunyai dubur, Allah memberikan ilham kepada buruk gagak untuk memakan ulat yang ada dalam mulut buaya (Munawwar, 2011:24-28).

Berpikir itu sendiri, menurut Al-Ghazali dalam kitab Ihya' Ulumuddin berarti mengahdirkan dua pengetahuan dalam hati untuk kemudian menghasilkan pengetahuan ketiga (ihdar ma'rifataini lil yastasmir minhuma ma rifah thalistah). Jadi, tafakkur pada hakikatnya adalah kegiatan mencari pengetahuan baru atas dasar pengetahuan-pengetahuan yang telah ada. Karena dengan tafakkur pengetahuan bertambah dan pengetahuan berkembang (Ismail Ilyas, 2013:231). Ibnu Khaldun membagi kesanggupan manusia untuk berpikir secara sistematis. Berpikir pada level tertinggi adalah bagaimana manusia dengan pengetahuan dan hipotesis untuk menemukan suatu sehingga tercipta tesis dan antitesis (Khaldun, 2014: 22-21). Kekuatan berpikir manusia dapat menyebabkan hal positif dan selalu mengarah kepada kebaikan tetapi tidak dengan kekuatan berpikir binatang. (Hariyanto, 2016: 113)Untuk menambah pengetahuan diperlukan berpikir tingkat tinggi (hingher order thingking) yaitu keterampilan berpikir yang mencakup keterampilan-keterampilan berpikir kritis, logis, reflektif, metakognitif dan kreatif (Achmad, 2016:63).

Pengembangan pikiran yang terlepas hubungannya dengan qolb akan menghasilkan pengetahuan lahiriah dari realitas yang ditangkap, sebaliknya qolb yang terlepas dari pikiran akan membuat sesorang hanya menangkap dimensi spiritual dari realitas yang ada. Secara moral ia mempunyai kesadaran yang tinggi, tetapi penguasaan tehnik dan teori menjadi sangat lemah, sebab dimensi fisik tidak dikuasai. Oleh karena itu sangat dituntut menghubungkan antara keduanya dalam hubungan yang proporsional. Hubungan yang proporsional tersebut akan menghasilkan hubungan yaang serasi antara pikir dan dzikir (Baharuddin, 2007:134).

Dengan menghasilkan pengetahuan (ilmu) melalui proses berfikir yang nantinya menjadikan manusia diangkat derajatnya oleh Allah karena berpengatahuan tinggi. Dengan pengetahuan itu manusia merealisasikan tujuan hidupnya yaitu mencapai kebahagiaan dunia dan akhirat. Dan kebahagian dunia 
dicapai dengan berpengatahuan sedangkan kebahagiaan akhirat dicapai dengan proses tazkiyatun nafs yaitu membersihkan hati melalui dzikir kepada Allah. Integrasi semacam ini diperlukan untuk menjadi manusia ulul albab.

\section{Integrasi Dzikir dan Fikir dalam Pendidikan Karakter}

Pendidikan karakter bukanlah merupakan ide yang baru dalam dunia pendidikan (Berkowitz \& Melinda, 2016:71). Sepanjang sejarah diseluruh dunia pendidikan telah memilki dua tujuan utama untuk menjadikan peserta didik menjadi baik dan menjadi pintar, dan peserta didik ini membutuhkan karakter bagi kedua tujuan tersebut (Lickona, 2004:4). Menurut Hellen H Douglas dalam Samani Muclas dan Hariyanto (2017:41), karakter tidak diwariskan, tetapi sesuatu yang dibangun secara berkesinambungan hari demi hari melalui pikiran dan perbuatan, pikiran demi pikiran, perbuatan demi perbuatan. Sedangkan dalam Maksudin (2013:3), karakter merupakan daya qolbu kualitas batiniah, cara berpikir dan berprilaku yang menjadi ciri khas setiap individu untuk hidup dan bekerja sama.

David dalam Zubaedi (2011:15), pendidikan karakter menjadi isu popular/trending topic dalam masalah pendidikan, bahkan bermunculan strategi, pendekatan, model pendidikan karakter dengan tujuan menumbuhkan karakter peserta didik. Pendidikan karakter adalah usaha sadar untuk membantu manusia memahami, peduli tentang, dan melaksanakan nilai-nilai etika inti. Dalam grand desain pendidikan karakter, pendidikan karakter merupaka proses pembudayaan dan pemberdayaan nilai-nilai luhur dalam lingkungan satuan pendidikan, keluarga, dan masyarakat.

Dalam kaitan itu diidentifikasi sejumlah nilai pembentuk karakter yang merupakan hasil kajian empirik pusat kurikulum nilai karakter tersebut adalah: (1) relegius (2) jujur (3) toleransi (4) disiplin (5) kerja keras (6) kreatif (7) mandiri (8) demokrasi (9) rasa ingin tahu (10) semangat Kebangsaan (11) cinta tanah air (12) menghargai prestasi (13) komunikatif (14) gemar membaca (15) peduli lingkungan (16) peduli sosial (17) cinta damai (18) tanggung jawab (Muclas \& Hariyanto, 2017:52). 
Pendidikan karakter sebagai upaya yang sungguh-sungguh untuk membantu seorang memahami, peduli, dan bertindak dengan landasan inti nilai-nilai etis. Komponen karakter baik component of good character (1) Moral knowing pengetahuan tentang moral (2) moral feeling, perasaan tentang moral (3) moral actions, perbuatan moral (Lickona, 2009). Proses pendidikan tersebut hanya menonjolkan aspek kognitif matrealistik saja yang jauh dari kontrol spiritualitas manusia. Proses pendidikan karakter tersebut hanya mengena pada akhlak lahiriyahluarnya saja tapi belum sampai pada titik point peserta didik yaitu hatinya (Damanhuri, 2007:42-45)Menurut Alba Hati sebagai wadah rahmat Allah, substansinya bersifat spiritual dan ini adalah esensi dari manusia. hati ini juga disebut Arsy Allah dan hati ini pula harus suci bersih (ahlak batiniyah). (Alba, Tasawuf dan Tarekat, 2012: 18) Sedangkan pembudayaan dan pemberdayaan nilai luhur manusia dalam pendidikan karakter pada organisasi psikis manusia itu bersumber pada al-aql (pengetahuan) dan al-qalb (Baharuddin, 2007:114).

Pendidikan karakter tidak hanya membentuk karakter intelektual tetapi juga membentuk karakter sikap dan perilaku. Strategi pendidikan karakter melalui kegiatan rutin dan pembiasaan yaitu kegiatan yang dilakukan terus menerus oleh peserta didik misalakan upacara bendera, salah dhuha berjamaah, berdoa sebelum pembelajaran. Pendidikan karakter dengan mengadopsi dan menginovasi pola pelaksanaan pendidikan budi pekerti dengan memiliki lima tahap menurut David $\mathrm{R}$ Krathwohl 35-36, (1) receiving, menyimak, (2) responding, menanggapi (3) valuing, memberi nilai (4) organizaion, mengorganisai nilai (5) characterization, karakterisasi nilai (Bloom, dkk, 1964:36).

Proses pendidikan karakter yang dijelaskan diatas kebanyakan adalah searah dengan cara mengembangkan kecerdasan akal saja. Kecerdasan qolb tidak pernah tersentuh sama sekali. Kecerdasan qolb hanya bisa diperoleh melalui proses tazkiyatun nafs dengan selalu berdikir. Qolb adalah kekuatan penentu dalam membangung perilaku, watak, karakter atau akhlak seorang. Hati yang baik akan menghasilakn perilaku yang baik begitu pula sebaliknya. Hati seorang bisa sehat dan bisa sakit (Suprayogo, 2013:12). Oleh sebab itu diperlukan pendidikan yang 
integral antara pendidikan karakter pada akal dan pendidikan karakter pada hati. Untuk menjadikan peserta didik berkarakter tidak cukup dengan pendidikan biasa yang seperti dalam pendidikan formal akan tetapi perlu pendekatan tazkiyatun nafs untuk menjadikan manusia beraklak terpuji (berkarakter). Analogi bahwa tasawuf adalah ruh dan ilmu yang lainya adalah jasad. Jadi, tidaklah bisa jasad hidup tanpa ruh, sedangkan ruh tanpa jasad bisa hidup (Alba, 2012:12-13).

Oleh karena itu karakter tidak hanya dibentuk melalui hanya sebatas lewat belajar mengajar atau pembelajaran. Kepribadian guru yang baik termasuk salah satu cara agar anak meniru karakter guru tersebut. Kepribadian guru yang mencerminkan perilaku relegius akan memicu peserta didik untuk meniru guru tersebut. Keteladan guru direfleksikan dalam kegiatan sehari-hari sehingga peserta didik terbiasa dengan kebiasaan tersebut. (Muhammad Anas Ma'arif, 2016: 50)

Pendidikan karakter dengan strategi pembiasan dzikir yang berorientasi pada penataan hati. Hati memegang peranan penting dakam kehidupan manusia karena baik dan buruknya manusia sangat bergantung pada kondisi hati. Dunia tasawuf mengenal hati dengan segala kompleksitasnya. Ada yang menyebut basyirah atau mata hati yang mempunyai potensi untuk melihat kebaikan dan keburukan. Konsepsi tersebut menunjukan bahwa dzikir merupakan pelathan hati untuk ber-musyahadah kepada Allah (Waqiatul, 2006:87-88).

Pendidikan karakter dengan metode tazkiyatus nafs (membersihkan hati) para sufi menetapkan tiga tahap (1) Takhalli (mengosongkan) (2) Tahalli (mengisi) (3) Tajalli (tercermin). Tahap mengosongkan adalah dengan megosongkan perbuatan dan amaliyah yang jelek dan tidak terpuji. Sedangkan tahap kedua adalah mengisi dengan nilai-nilai dan amalan amalan yang baik. Proses kedua ini juga bisa dicapai melalui aktifitas dzikir. Dan dzikir juga memiliki proses dari dzikir lisan, jahr sampai ke dzikir haqiqi yang mana seluruh anggota badan berdzikir semua. Tahaptajalli adalah terbukanya nur gaib bagi hati. (Zubaedi, 2011:132-36).

Pendidikan karakter tidak hanya membentuk karakter intelektual tetapi juga membentuk karakter sikap dan perilaku. Strategi pendidikan karakter melalui kegiatan rutin dan pembiasaan yaitu kegiatan yang dilakukan terus menerus oleh 
peserta didik misalakan upacara bendera, salah dhuha berjamaah, berdoa sebelum pembelajaran. Pendidikan karakter dengan mengadopsi dan menginovasi pola pelaksanaan pendidikan budi pekerti dengan memiliki lima tahap menurut David $\mathrm{R}$ Krathwohl 35-36, (1) receiving, menyimak, (2) responding, menanggapi (3) valuing, memberi nilai (4) organizaion, mengorganisai nilai (5) characterization, karakterisasi nilai (Bloom, dkk, 1964:36).

Proses pendidikan karakter yang dijelaskan diatas kebanyakan adalah searah dengan cara mengembangkan kecerdasan akal saja. Kecerdasan qolb tidak pernah tersentuh sama sekali. Kecerdasan qolb hanya bisa diperoleh melalui proses tazkiyatun nafs dengan selalu berdikir. Qolb adalah kekuatan penentu dalam membangung perilaku, watak, karakter atau akhlak seorang. Hati yang baik akan menghasilakn perilaku yang baik begitu pula sebaliknya. Hati seorang bisa sehat dan bisa sakit (Suprayogo, 2013:12). Oleh sebab itu diperlukan pendidikan yang integral antara pendidikan karakter pada akal dan pendidikan karakter pada hati. Untuk menjadikan peserta didik berkarakter tidak cukup dengan pendidikan biasa yang seperti dalam pendidikan formal akan tetapi perlu pendekatan tazkiyatun nafs untuk menjadikan manusia beraklak terpuji (berkarakter). Analogi bahwa tasawuf adalah ruh dan ilmu yang lainya adalah jasad. Jadi, tidaklah bisa jasad hidup tanpa ruh, sedangkan ruh tanpa jasad bisa hidup (Alba, 2012:12-13).

Oleh karena itu karakter tidak hanya dibentuk melalui hanya sebatas lewat belajar mengajar atau pembelajaran. Kepribadian guru yang baik termasuk salah satu cara agar anak meniru karakter guru tersebut. Kepribadian guru yang mencerminkan perilaku relegius akan memicu peserta didik untuk meniru guru tersebut. Keteladan guru direfleksikan dalam kegiatan sehari-hari sehingga peserta didik terbiasa dengan kebiasaan tersebut. (Muhammad Anas Ma'arif, 2017: 40)

Pendidikan karakter dengan strategi pembiasan dzikir yang berorientasi pada penataan hati. Hati memegang peranan penting dakam kehidupan manusia karena baik dan buruknya manusia sangat bergantung pada kondisi hati. Dunia tasawuf mengenal hati dengan segala kompleksitasnya. Ada yang menyebut basyirah atau mata hati yang mempunyai potensi untuk melihat kebaikan dan 
keburukan. Konsepsi tersebut menunjukan bahwa dzikir merupakan pelathan hati untuk ber-musyahadah kepada Allah (Waqiatul, 2006:87-88).

Pendidikan karakter dengan metode tazkiyatus nafs (membersihkan hati) para sufi menetapkan tiga tahap (1) Takhalli (mengosongkan) (2) Tahalli (mengisi) (3) Tajalli (tercermin). Tahap mengosongkan adalah dengan mengosongkan perbuatan dan amaliyah yang jelek dan tidak terpuji. Sedangkan tahap kedua adalah mengisi dengan nilai-nilai dan amalan amalan yang baik. Proses kedua ini juga bisa dicapai melalui aktifitas dzikir. Dan dzikir juga memiliki proses dari dzikir lisan, jahr sampai ke dzikir haqiqi yang mana seluruh anggota badan berdzikir semua. Tahaptajalli adalah terbukanya nur gaib bagi hati.(Zubaedi, 2011:132-36).

Efek dzikir memunculkan sikap rendah hati, tidak sombong, karena kemampuan manusia ada batasnya. Selalu intropeksi diri, beraklakul karimah . (Subandi Psikologi dzikir, 218) Subandi menyimpulkan paling tidak ada tujuh karakter yang muncul dari seorang yang telah mengamalkan dzikir secara intensif yaitu: (1) kemampuan memecahkan masalah baik masalah pribadi, sosial, politik dan ekonomi (2) ketahan emosianal yang tinggi (3) ketenangan bathin, tidak cemas (4), kontrol diri, pengendalian diri, tidak terbawa arus kemanapun dia pergi, kususnya remaja yang kurang bisa mengontrol diri. (5) pemahaman terhadap dirinya secara baik. Siapa aku siapa Allah (6) menemukan jati dirinya (7) kesadaran super moral (Alba, 2012:170-72).

Dengan demikian bahwa pendidikan karakter tidak bisa dilakukan setengahsetengah. Perlu intregrasi yang menyeluruh sehingga tidak terjadi ketimpangan. Mengingat tujuan dari pendidikan karakter adalah membentuk peserta didik yang bisa mengamalkan nilai-nilai karakter. Nilai-nilai karakter tidak didapatkan secara instan akan tetapi diperlukan waktu dengan cara pembiasaan baik secara intelektual atau spiritual, baik secara belajar yang berkesinambungan atau berdzikir secara continu. Dengan konsep integrasi antara dzikir dan pikir inilah bisa memunculkan pendidikan karakter tanpa dikotomik. Hasil yang didapatkan juga sangat komprehensif. 
Peserta didik tidak hanya di ajak untuk berdzikir saja tetapi juga diajak berpikir. Berpikir juga berarti belajar tentang ilmu pengetahun. Berdzikir diperlukan pembiasan begitu juga berpikir. Dengan pembiasan berdzikir maka peserta didik bisa mengamalkan nilai-nilai karakter dan menjadi jati dirinya. Berpikir tidak hanya dibiasakan tetapi perlu cara-cara yang tepat untuk mengajak peserta didik berpikir sistematis dan logis maka perlu memberikan gaya belajar/berpikir yang sesuai dengan kebutuhan peserta didik, karena pada dasarnya peserta didik sudah dibekali intelejensi masing-masing dan di tiap peserta didik memiliki intelegensi yang berbeda-beda. (J Federick, 1965: 158)

Beberapa cara berpikir yang harus dibudayakan oleh umat Islam adalah sebagai berikut (Qomar, 2015: 56-58):

1. Berpikir kreatif dan mandiri, mampu menghadirkan hal-hal baru yang belum dikerjakan orang lain baik substansi, model, bentuk dan karakteristiknya.

2. Mempersiapkan modal pengetahuan ganda.

3. Berpikir untuk menciptakan model baru. Baik model pendidikan, pembelajaran atau model-model yang lainya.

4. Berpikir untuk mengajari orang lain tidak hanya berpikir untuk belajar.

5. Berpikir untuk menandingi prestasi orang lain.

6. Berpikir mengembangkan naluri pengubah secara konstruktif

7. Berpikir menjadi pengedali peradaban secara arif dan bijaksana.

Dari cara berpikir dan gaya belajar itulah dikompromikan dengan komponen karakter baik (component of good characters) yang digagas oleh Lickona dari moral knowing, moral feeling dan moral actions akan dilengkapi dan di integrasikan dengan komponen tazkiyatun nafs, yaitu takhalli, tahalli dan tajalliagar mendapat pengetahaun yang menyeluruh. Dengan strategi pembiasaan baik disekolah, di lingkungan keluarga dan di lingkungan masyarakat akan memungkinkan untuk mencetak peserta didik dengan berperilaku sesuai nilai-nilai pendidikan karakter. Tidak hanya berakhlak lahiriyah saja tetapi berakhlak batiniyah. Sehinga tercipa peserta didik yang intelektualnya tinggi karena selalu 
berpikir tentang pengetahuan dan menjadi ulama`yang menjadi panutan ummat, (intelek yang ulama`atau ulama yang intelek).

\section{KESIMPULAN}

Dzikir tidak hanya bermakna mengingat dan menyebut Allah tetapi segala hal yang bertujuan taqwa kepada Allah disebut sebagai dzikir. Berfikir tentang ciptaan Allah lebih utama dari hanya sebatas berdzikir. Berfikir secara sitematis dan logis dengan bertujuan mengembangkan ilmu pengetahuan. Dzikir dan fikir merupakan suatu kesatuan yang tidak bisa dipisahkan dalam kehidupan manusia sehingga keduanya saling mengisi satu sama lain untuk membentuk manusia yang utuh (ulul albab). Ketika dimensi dzikir yang berorientasi membentuk hati yang bersih maka dimensi fikir membentuk manusia yang berintelektual tinggi (akal yang sempurna). Implikasi integrasi dzikir dan fikir akan membentuk konsep pendidikan yang integral tanpa dikotomi. Dari komponen moral knowing, moral feeling dan moral action yang digabung dengan tazkiyatun nafs di harapkan mampu membentuk peserta didik mengamalkan nilai-nilai yang termaktub dalam tujuan pendidikan karakter. 


\section{DAFTAR PUSTAKA}

Alba, H. Cecep. Tasawuf dan Tarekat: Dimensi Esoteris Ajaran Islam. Cet. 1. Bandung: Anggota Ikapi, 2012.

Azra, Azyumardi. Pendidikan Islam: tradisi dan modernisasi di tengah tantangan milenium III. Jakarta: Kencana, 2012.

Baharuddin. Paradigma Psikologi Islami, Studi tentang Elemen Psikologi dari AlQur`an. 2 ed. Yogyakarta: Pustaka Pelajar, 2007.

Berkowitz, Marvin W., dan Melinda C. Bier. "Research-Based Character Education." The ANNALS of the American Academy of Political and Social Science, 8 September 2016. https://doi.org/10.1177/0002716203260082.

Bloom, Benjamin S, David R Krathwohl, dan Bertram S Masia. Taxonomy of Educational Objectives: The Classification of Educational Goals. New York: Longman, 1964.

Damanhuri. Akhlak Perspektif Tasawuf Syaikh Abdurrahman As-Singkili. Jakarta: Gramedia Widiasarana Indonesia, 2007.

Federick, J. Educational Psychology. Wadsworth: Publishing Company, 1965.

Fuad Abdul Baqi`. Mu jam al-Muafarras. 2 ed. Beirut Lebanon: Dar al-Kotob AlIlmiyah, 2010.

Hariyanto, dan Fibriana Anjaryati. "Character Building: Telaah Pemikiran Ibnu Miskawaih Tentang Pendidikan Karakter.” Jurnal Pendidikan Islam Indonesia 1, no. 1 (10 Oktober 2016): 111-18.

Ibnu Mandzur. Lisanul Arab. 2 ed. 4 vol. Beirut Lebanon: Dar al-Kotob AlIlmiyah, 2010.

Ilyas, Ismail. True Islam, Moral, Intelektual, Spiritual. Jakarta: Mitra Wacana Media, 2013.

Ismail bin Umar, Damasqy. Tafsir Ibnu Katsir. 3 ed. 4 vol. Beirut Lebanon: Dar al-Kotob Al-Ilmiyah, 2010.

Ismail, Nawawi. Tarekat Qodiriyah Naqsabandiyah, Sebuah Kajian Ilmiyah dan Amaliyah. Surabaya: Karya Agung, 2008. 
Khaldūn, Ibn. Muqoddimah Ibnu Khaldun. Diterjemahkan oleh Thoha Ahmadie.

12. Jakarta: Pustaka Firdaus, 2014.

Kharisuddin, Aqib. Al-Hikmah, Memahami Teosofi Tarekat Qodiriyah Naqsabandiyah. Surabaya: Dunia Ilmu, 2000.

Lickona, Thomas. Character matters: how to help our children develop good judgment, integrity, and other essential virtues. New York: Simon \& Schuster, 2004.

- Educating for Character: How Our Schools Can Teach Respect and Responsibility. New York: Bantam Books, 2009.

Ma`arif, Muhammad Anas. "Dhikr and Thinking Integration as Non-Dicotomic Character Education Development | Proceeding International Conference on Islamic Education (Icied)," 16 Februari 2018. http://conferences.uinmalang.ac.id/index.php/icied/article/view/435.

__. "Pendidikan Islam Dan Tantangan Modernitas." Nidhomul Haq: Jurnal Manajemen Pendidikan Islam 1, no. 2 (26 Maret 2016): 47-58.

Ma’arif, Muhammad Anas. “Analisis Konsep Kompetensi Kepribadian Guru PAI Menurut Az-Zarnuji.” ISTAWA 2, no. 2 (2017): 35-60.

Majid, Nurcholish, dan Budhy Munawar Rachman. Ensiklopedi Nurcholish Madjid: pemikiran Islam di kanvas peradaban. Cet. 1. Jakarta: Paramadina, 2006.

Maksudin. Pendidikan karakter non-dikotomik. Cet. 1. Yogyakarta: Pustaka Pelajar, 2013.

Muclas, Samani, dan Hariyanto. Konsep dan Model Pendidikan karakter. 6 ed. Bandung: Rosdakarya, 2017.

Muh, Mu`inudinillah. 24 Jam dzikir dan Do`a Rasulallah. Surakarta: Biladi, 2014.

Muhammad bin Abu Bakar, Al-Qurtuby. Tafsir Qurtuby. 3 ed. 4 vol. Beirut Lebanon: Dar al-Kotob Al-Ilmiyah, 2010.

Muhammad Munawwar, Kholil. Badrul Alam. Gresik: PP Daruttaqwa, 2007.

—. Faidul Illah fi Fadli Dizkri Allah. Gresik: PP Daruttaqwa, 2011. 
Qomar, Mujamil. Pemikiran Islam Metodologis, Model Pemikiran Alternatif Dalam Memajukan Islam. Yogyakarta: Kalimedia, 2015.

Riyadi, Agus. 'Zikir dalam al-qur'an sebagai terapi psikoneurotik (analisis terhadap fungsi bimbingan dan konseling islam).” Konseling Religi Jurnal Bimbingan Konseling Islam 4, no. 1 (2014): 5370.https://doi.org/10.21043/kr.v4i1.1070.

S. Nasution. Metode Research (penelitian Ilmiah). 14 ed. Jakarta: Bumi Aksara, 2014.

Sanusi Achmad. Pendidikan untuk Kearifan, Mempertimbangkan Kembali Sistem Nilai, Belajar dan Kecerdasan. Bandung: Nuansa, 2016.

Subandi, M A. Psikologi Dzikir Fenomonologi Pengalaman Tranformasi Relegius. Yogyakarta: Pustaka Pelajar, 2009.

Suprayogo, Imam. Pengembangan pendidikan karakter. Malang: UIN Maliki Press, 2013.

Syamsul, Munir. Energi Dzikir. Jakarta: Amzah, 2014.

Tafsir, Ahmad. Filsafat Pendidikan Islam, Integrasi Jasmani, Rohani dan Kalbu memanusiakan manusia. Bandung: Remaja Rosdakarya, 2012.

Waqiatul, Masrurah. Praktik Mengajar 1. Surabaya: CV Salsabila Pratama, 2006.

Wina, Sanjaya. Kurikulum dan Pembelajaran: Teori dan Praktik Pengembangan Kurikulum Tingkat Satuan Pendidikan (KTSP). 6 ed. Jakarta: Kencana Prenada Media Group, 2015.

Zed, Mestika. Metode penelitian kepustakaan. Ed. 2. Jakarta: Yayasan Obor Indonesia, 2008.

Zubaedi. Desain Pendidikan karakter, Konsepsi dan Aplikasinya dalam Pendidikan. Jakarta: Kencana Prenada, 2011. 